outcomes, and provide substantial opportunities for creating long-lasting reductions in STI rates.

\section{P4.79 THE DISTRIBUTION OF SEX PARTNERS IN THE UNITED STATES BY SEXUAL IDENTITY: DATA FROM THE NATIONAL SURVEY OF FAMILY GROWTH}

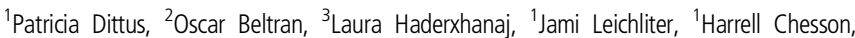
${ }^{1}$ Sevgi Aral. ${ }^{1}$ Centres for Disease Control and Prevention, Atlanta, USA; ${ }^{2}$ OAK Ridge Institute for Science and Education, Atlanta, USA; Indiana University Bloomington, Bloomington, USA

\subsection{6/sextrans-2017-053264.574}

Introduction Risky sexual behaviour and STIs cluster within subpopulations. Examining the concentration of behaviours can help to target interventions to those at highest risk. Given STI disparities by sexual identity, we examined the distribution of sexual partners among heterosexual, homosexual, and bisexual males and females.

Methods Data from the 2006-15 U.S. National Survey of Family Growth were used to analyse the number of oppositesex and same-sex partners in the past 12 months, focusing on means and the percentage of sex partners accounted for by the top $20 \%$ of each subpopulation; $95 \%$ confidence intervals were used to examine significant differences. Demographics will also be reported.

Results Bisexual women reported a higher mean number of recent opposite-sex partners $(1.81 ; 95 \% \mathrm{CI}: 1.66,1.96)$ than heterosexual $(1.21 ; 95 \% \mathrm{CI}: 1.19,1.24)$ and homosexual $(0.79$; 95\% CI: $0.26,1.32)$ women, whereas homosexual women reported a higher number of same-sex partners (1.55; 95\% CI: $1.39,1.72)$ than bisexual $(0.74 ; 95 \% \mathrm{CI}: 0.64,0.84)$ and heterosexual women $(0.21 ; 95 \% \mathrm{CI}: 0.17,0.25)$. Within each subgroup, the top $20 \%$ of bisexual and heterosexual women accounted for $45 \%$ and $37.6 \%$ of opposite-sex partners, respectively. Among males, there was no difference in the mean number of recent opposite-sex partners between heterosexual and bisexual men (1.5 partners), whereas homosexual men reported a significantly higher mean number of recent same-sex partners $(2.39 ; 95 \% \mathrm{CI}: 2.11,2.67)$ than bisexual (1.16; 95\% CI: $0.87,1.45)$ and heterosexual men $(0.18 ; 95 \% \mathrm{CI}: 0.12,0.24)$. Within each subgroup, the top $20 \%$ of heterosexual men accounted for $47.1 \%$ of oppositesex partners compared to the top $20 \%$ of gay and bisexual men accounting for $48.1 \%$ and $59.8 \%$ of same-sex partners, respectively.

Conclusions In general, sexual minorities reported higher numbers of recent sex partners, however, interesting gender differences emerged, particularly with regard to the top $20 \%$ of subpopulations. Interventions targeting high-risk persons within sub-populations may be more impactful.

\section{P4.80 EMPOWERING ADOLESCENTS THROUGH ART EDUCATION FOR SEXUAL HEALTH PROMOTION}

${ }^{1}$ Patricia Neyva da Costa Pinheiro, ${ }^{2}$ Anny Gisely Milhome da Costa Farre, ${ }^{1}$ Fabiane do Amaral Gubert, ${ }^{1}$ Neiva Francenely Cunha Vieira. ${ }^{1}$ Universidade Federal do Ceará, Fortaleza - CE, Brazil; ${ }^{2}$ Universidade Federal de Sergipe, Lagartos - SE, Brazil

10.1136/sextrans-2017-053264.575
Introduction The objective of this study was to evaluate the contributions of Art Education for sexual health promotion of adolescents in the context of urban social vulnerability, through the process of consciousness and empowerment.

Methods Community-based participatory research developed with 21 adolescents who were participating in a governmental program of Art Education and resocialization located in a Brazilian poor community. Data were collected in five months by Fetterman's method of Empowerment Evaluation through weekly group meetings and participant observation by critical friends. Data analysis was supported by Freire's concepts of Critical Consciousness with a qualitative approach to data categorization.

Results Adolescents oriented their needs and priorities of health into two main themes and their categories: 1) Community: health care, diseases, trafficking, violence, drugs and leisure; 2) Adolescence: body, mind, friendships, dating, sex and fun. The Art Education activities - visual, audiovisual and dance - were articulated with reflections about these subjects and showed the power of community relationships in sexual health promotion of adolescents. Some changes were observed after reevaluation of the process and involved the triad: individual, community and program. A predominantly negative view of the neighbourhood was becoming a vision full of possibilities, examples and personal empowerment for health and wisely choices.

Conclusion This research proposed a model of Adolescent Health Promotion Based on Art Education and CommunityCentred. The group walked towards intransitive consciousness, for the transitive-naive and critical, featuring an awareness process that began with the seizure of a health reality initially considered fateful and immutable, past the living situations that favoured the questioning of this reality and culminated with the perception of the possibilities of change and selfdetermination for change.

\section{P4.81 ADOLESCENT CHAT: MOBILE APPLICATION ON SEXUALITY, STD/HIV/AIDS PREVENTION}

${ }^{1}$ Patricia Neyva da Costa Pinheiro, ${ }^{2}$ Mariana Borges Sodré, ${ }^{3}$ Thailane Maria Silva Santana, ${ }^{2}$ Adrian Gomes Nogueira Ferreira, ${ }^{4}$ Geraldo Braz Junior. 'Universidade Federal do Ceará, Fortaleza - CE, Brazil; ${ }^{2}$ Universidade Federal do Maranhão, Imperatriz - MA, Brazil; ${ }^{3}$ Universidade Federal do Maranhão, Imperatiz - Ma, Brazil; ${ }^{4}$ Universidade Federal do Maranhão, São Luis - MT, Brazil

\subsection{6/sextrans-2017-053264.576}

Introduction The popularisation of mobile devices has been considered by many to be the technological revolution of greatest impact in recent years. Thus, the development of computational solutions in the form of applications for mobile devices represents an effective means of making available health education contents for adolescents. The objective of the study was to describe the development of the application Adolescent Chat with information on sexuality and STD/HIV/ AIDS prevention.

Methods This is a research and methodological development, carried out in 2016. In this study, an application was developed based on the website already developed, Adolescent Chat, containing subjects on sexuality and STD/HIV/AIDS prevention as a tool to promote Adolescents that attend the Catholic Church. Ethical aspects were respected in accordance with protocol No. 1.165.118. 